\title{
Design of biofunctional molecular and supramolecular systems: Membrane transport models
}

\author{
KOJI ARAKI \\ Institute of Industrial Science, University of Tokyo, 7-22-1 Roppongi, Minato-ku, \\ Tokyo 106, Japan

\begin{abstract}
Cell membranes show a variety of functions that are essential for cell survival. Among them, active transport is a typical high functionality that the biomembrane system has realized. To understand and mimic the functionality of the biomembrane transport systems, carrier-mediated active transport systems are studied. Affinity switching of the carrier, i.e., high substrate affinity in the extraction and low affinity in the release processes, is the effective approach to achieve artificial active transport. Free energy to drive this active transport is supplied in the affinity-swtiching process. This paper describes our recent results on design and performance of novel molecular and supramolecular active transport systems, in which carriers are designed by the affinity-switching concept.
\end{abstract}

Keywords. Biofunctional systems; membrane transport modeis; substrate affinity.

\section{Introduction}

\subsection{Active transport in biological systems}

Cells are the smallest unit of organisms, which are separated from outside by cell membranes. The cell membranes not only serve as barriers but show varieties of capabilities indispensable for cell survival. Through or on the cell membranes, translocation of substrates, transduction of one form of energy into another, and transformation of physical or chemical signals are performed. These are the typical functions of the biomembrane systems. Among them, active transport is a typical high functionality of the biomembrane system.

Active transport is the process by which a substrate is transported against its electrochemical potential gradient, and requires another free energy source to couple with. Primary active transport is operated by coupling with another free energy source. A group of enzymes called ATPase utilizes ATP hydrolysis as the free energy source, and bacteriorhodopsin mediates active transport of protons by photo-irradiation. Secondary active transport is directly driven by ionic gradients. Active transport of glucose and amino acid into some animal cells requires simultaneous entry of $\mathrm{Na}^{+}$, a process called cotransport. The concentration gradient of $\mathrm{Na}^{+}$is the driving force behind active transport.

Active transport plays a variety of important roles in biological systems. Though the process requires free energy to operate, various functions that are essential for living activities are realized by active transport. For example, active transport by ATPase in neurons generates asymmetric distribution of cations across the membrane, and the resultant membrane potential is indispensable for signal transmission and processing within the neurons. 


\subsection{Carrier-mediated transport}

A biomembrane is a highly ordered supramolecular system consisting of lipids, proteins and carbohydrates. The lipid bilayer is the principal structure of the biomembrane, which provides two-dimensional liquid-like media. Most hydrophilic substances cannot permeate through the hydrophobic interior of the lipid bilayer. Though structures of ATPase and other transport proteins have been the subject of intense studies (Cross 1994; Bogdanov and Dowhan 1995; Jessenmarshall et al 1995; Lanyl 1995) molecular-level understanding of their functions requires further studies.

Membrane transport is also induced by relatively simple peptides, oligopeptides, or other biomolecules. These compounds serve as either carriers or channels across the membrane. Since carrier molecules have relatively simple structures, carrier-mediated transport system is an accessible and practical target and has been investigated extensively as a model of the biological membrane transport system (Lehn 1988). Carrier molecules in the organic membrane phase mediate facilitated transport of hydrophilic substrates by increasing the intramembrane concentration gradient of the substrates (figure $1 \mathrm{~b}$ ). There are various naturally-occurring and chemically modified jonophores in both cyclic and acyclic forms. However, relatively few anion carriers have been reported.

\subsection{Affinity-switching strategy for an active transport model}

Construction of an artificial active transport system is a challenging target. One possible approach is to induce cotransport or coupled flow with other species. Coupled flow of more than two species either in the same (symport) or in the opposite (antiport) direction provides a way to utilize the concentration gradient of other species. The term "uphill transport" is frequently used for this type of active transport. Until now, many groups have examined uphill transport of various substrates by coupling with the chemical potential difference of protons through the membrane (Kishii et al 1985; Hiratani et al 1992; Lucia et al 1992). However, most of them required a large $p \mathrm{H}$ difference in order to achieve noticeable uphill transport because of relatively low transport efficiency.

One reason for this poor performance is the contradictory demand for the substrate affinity of the carrier. Higher substrate affinity is desirable for efficient uptake of the substrate, but affinity in the release process should be low in order to facilitate substrate discharge. Affinity switching of the carrier during the transport process can be the answer to this dilemma, i.e., high substrate affinity in the uptake process but low affinity in the release process. When alteration of the substrate affinity is sufficiently large, the

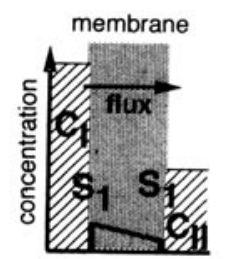

(a)

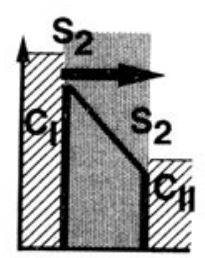

(b)

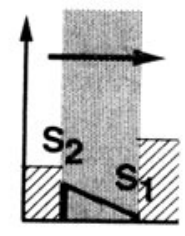

(c)

Figure 1. Type of membrane transport: (a) diffusion, (b) facilitated and (c) active transport. Substrate is transported from the aqueous phase $\mathrm{I}$ (concentration $C_{\mathrm{I}}$ ) to the aqueous phase II $\left(C_{\text {II }}, C_{I}>C_{\text {II }}\right)$ through a membrane (solubility in the membrane-S). 
concentration gradient of the substrate inside the membrane can be reversed (figure 1c). This reverse concentration gradient inside the membrane induces active transport of the substrate against the concentration difference between two external water phases. Free energy to drive this active transport system is supplied by the affinity-switching process of the carrier.

Photo-induced affinity switching of the carrier allows us to design a primary active transport model, while a secondary active transport model can be designed by $p H$ induced-affinity switching of the carrier. In this article, we will show that the affinityswitching concept is effective for designing an artificial active transport system.

\section{Photo-driven active transport}

2.1 Design and tuning of photo-driven active transport systems for anions by triarylcation carriers

In principle, switching of the affinity of the carrier by photo-irradiation can induce photo-driven active transport (Seno and Araki 1993). Several groups have reported the functional carriers that can alter their substrate affinities by a photochemical process (Shinkai et al 1982; Shimizu and Yoshizawa 1983; Irie and Kato 1985; Winkler et al 1989). However, most of them showed only improved facilitated transport rather than active transport. The inability to induce active transport by most of these carriers does not weaken the usefulness of the affinity-switching concept, since many factors other than photo-response have to be tuned properly in order to realize active transport.

In a photo-responsive carrier, a large alteration of substrate affinity is required to induce noticeable active transport. For this we selected triarylmethanol $(\mathrm{C}-\mathrm{OH})$ derivatives as the anion carrier (Ino et al 1994a). They undergo reversible dissociation into triarylcation $\left(\mathrm{C}^{+}\right)$ and hydroxide ion $\left(\mathrm{OH}^{-}\right)$by photo-irradiation (scheme 1). Neutral $\mathrm{C}-\mathrm{OH}$ in an organic phase does not bind anions, while photo-generated $\mathrm{C}^{+}$has an ability to extract anions from an aqueous phase by electrostatic interaction. Four different triarylmethanol derivatives, $\underline{1}-\underline{4}$, were used in this study in order to tune the active transport system.

2.1a Photo-driven active transport by triarylmethanol 1 : First we tested the transport of a lipophilic anion, $p$-toluenesulfonate (tosylate), by triarylmethanols $\underline{1}$ and $\underline{2}$. Two identical aqueous solutions containing tosylate $(2.00 \mathrm{mM})$ were separated by
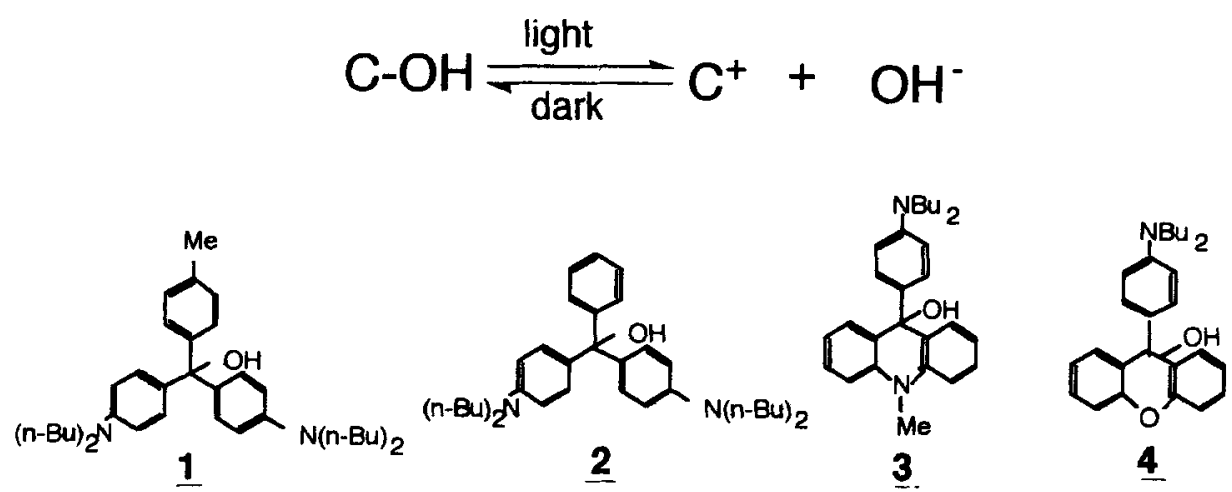

Scheme 1. Triarylmethanol-type carriers. 


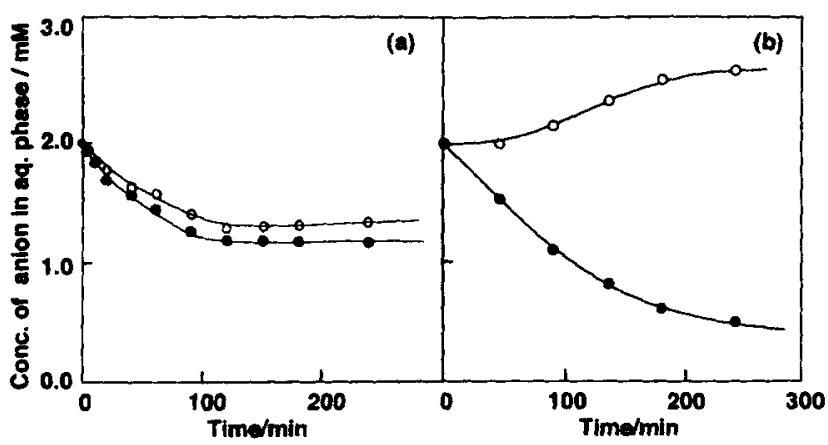

Figure 2. Transport of (a) $p$-toluenesulfonate and (b) bromide by triarylmethanol 1. Anion concentrations of the aqueous solutions at the illuminated $(\boldsymbol{O})$ and dark (O) side.

a carrier/1,2-dichloroethane solution $(2.00 \mathrm{mM})$, and one side of the interface was illuminated by UV-light $(300 \mathrm{~nm}<\lambda<400 \mathrm{~nm})$. No active transport was mediated by 1 (figure $2 \mathrm{a}$ ), and tosylate concentrations in both aqueous phases $(p \mathrm{H} 14)$ decreased upon photo-irradiation.

To understand this poor performance of photo-responsive carriers, we analyzed the transport process of the carrier 1 based on the following three stages and determined the half-lives of reactions (1)-(5).

(A) Photo-induced dissociation and association ((1) and (2)), and $\mathrm{OH}^{-}$-catalyzed association of the carrier, (3).

(B) Uptake of anions $\left(\mathrm{X}^{-}\right)$at the illuminated-side of the interface from an aqueous to an organic phase by anion-exchange of $\mathrm{C}^{+} \mathrm{OH}^{-}$with $\mathrm{X}^{-}$to form an ion pair $\left(\mathrm{C}^{+} \mathrm{X}^{-}\right),(4)$.

(C) Release of anions at the dark-side of the interface by reaction of $\mathrm{C}^{+} \mathrm{X}^{-}$with $\mathrm{OH}^{-}$ in the aqueous phase to become $\mathrm{C}-\mathrm{OH},(5)$.

The half-life profile of the tosylate transport by 1 is shown in figure 3a. Reaction (2) is too slow to observe and can be neglected. The half-lives of processes represented by (1), (3) and (4) are less than $10 \mathrm{~min}$, but that of the release process, (5), is $200 \mathrm{~min}$. This poor release ability rationalized that the increase of tosylate concentration was not observed in the transport experiment. Thus, the release process is found to be the rate-limiting step. The release rate of the carrier $\underline{2}$ is even slower than that of $\underline{1}$, and no active transport was induced by 2 .

To enhance the release process, we studied the half-lives of the release process (5) for various anions by 1 (table 1 ). The release rate of bromide is relatively fast, but its rate of uptake is not significantly diminished. Indeed, bromide is efficiently transported from the illuminated side to the dark side against its concentration gradient (figure $2 \mathrm{~b}$ ). The half-life profile of the bromide transport (figure $3 \mathrm{~b}$ ) indicates that the release process is greatly improved though it is still the rate-limiting step.

2.1b Efficient transport by more reactive carriers: Decrease of the stability of the photo-generated triarylcation can be another strategy for accelerating the release rate. Xanthenol derivatives undergo reversible photo dissociation into xanthylium cation $\left(\mathrm{C}^{+}\right)$and $\mathrm{OH}^{-}$(MaClelland et al 1989). In general, the xanthylium cation $\left(\mathrm{C}^{+}\right)$is less stable and is more reactive with $\mathrm{OH}^{-}$to give xanthenol (C-OH) (2) and (3), and 


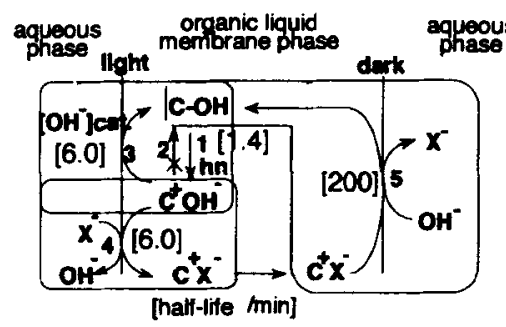

(a)

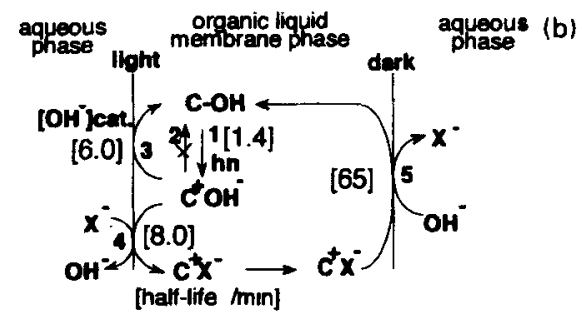

Figure 3. The half-life profiles of the reactions in photo-driven transport of (a) p-toluenesulfonate and (b) bromide.

Table 1. Half-lives for anion uptake and release by $\underline{1}$.

\begin{tabular}{lcc}
\hline Anion & $t_{\frac{1}{2}}$ for $(4)(\mathrm{min})$ & $t_{\frac{1}{\frac{1}{2}}}$ for $(5)(\mathrm{min})$ \\
\hline$p$-Toluenesulfonate & 6.0 & 200 \\
p-Toluenesulfonate & 6.0 & 500 \\
Benzenesulfonate & 6.5 & 130 \\
$m$-Nitrobenzenesulfonate & 5.9 & 300 \\
$\mathrm{Br}^{-}$ & 8.0 & 65 \\
$\mathrm{NO}_{3}^{-}$ & 6.5 & 80 \\
$\mathrm{ClO}_{4}^{-}$ & 15.9 & $\mathrm{a}$ \\
\hline
\end{tabular}

${ }^{\mathrm{a}}$ Too slow to estimate; ${ }^{\mathrm{b}}$ carrier 2

therefore, faster release of the bound anion is expected by xanthenols $\underline{3}$ and 4 . Unlike carriers 1 and 2 , the photo-generated $\mathrm{C}^{+} \mathrm{OH}^{-}$from $\underline{3}$ and $\underline{4}$ easily went back to the alcoholic form $(\mathrm{C}-\mathrm{O}-\mathrm{OH})$ in 1,2-dichloroethane without contact with the aqueous phase, showing that the cationic forms of $\underline{3}$ and $\underline{4}$ are less stable. Half-lives of the association $\left(t_{\frac{1}{2}-2}\right),(2)$, and the $\mathrm{OH}^{-}$-catalyzed association $\left(t_{\frac{1}{2}-3}\right),(3)$, of $\underline{3}$ and 4 are summarized in table 2. Figure 4 shows the photo-induced active transport of tosylate mediated by $\underline{3}$ and 4 . It is apparent that the transport efficiency is improved by using the more reactive carrier $\underline{3}$. This situation is explained by the increased release rate, demonstrating that the tuning of the stability of the photo-generated cation is also effective in achieving efficient active transport. On the other hand, carrier $\underline{4}$ showed poor transport ability. The cationic form of carrier $\underline{4}$ is so unstable that the concentration of $\mathrm{C}^{+}$under irradiation is not high enough to induce sufficient extraction of tosylate. 
Table 2. Half-lives/min for equations (1), (2), (3), (4) and (5) of carriers $\underline{3}$ and $\underline{4}$.

\begin{tabular}{lccccc}
\hline & \multicolumn{5}{c}{ Half-lives $\left(t_{\frac{1}{2}}\right)$} \\
\cline { 2 - 6 } Carrier & $(1)$ & $(2)$ & $(3)$ & $(4)$ & $(5)$ \\
\hline 3 & 1.4 & 180 & $2 \cdot 6$ & 7.2 & 35 \\
$4^{a}$ & 1.2 & 2.0 & 1.1 & 7.0 & 7.0 \\
\hline
\end{tabular}

${ }^{a}$ Because of the low stability of the cationic form, $p \mathrm{H}$ of the aqueous solution was set at $12 \cdot 0$

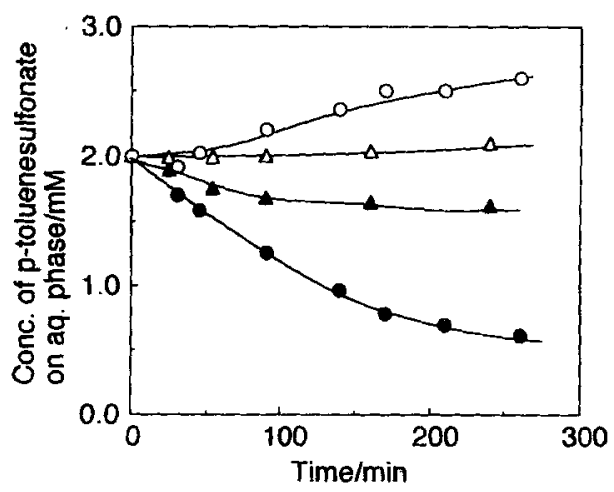

Figure 4. Photo-driven transport of $p$-toluenesulfonate by xanthenols $\underline{3}$ and 4 . Anion concentrations of the aqueous solutions at the illuminated $(0)$ and dark $(O)$ side by $\underline{3}$, and the illuminated $(\Delta)$ and dark $(\Delta)$ side by $\underline{4}$.

Thus, photo-driven active transport of anions by triarylcation is generated by selecting hydrophilic anions or by controlling the stability of the triarylcations. The results demonstrated that the tuning of the molecular transport system is essential for designing the artificial active transport system.

\subsection{Design of photo-responsive supramolecular carriers for photo-controlled extraction} and active transport of amino acids

Though normal and reversed micelles are simple aggregates of amphiphilic molecules in water and apolar media, respectively, they offer a unique microenvironment different from bulk media. This unique microenvironment can easily be tuned by selection of surfactant, concentration, solvent or other factors and, therefore, is useful for designing the hydrophobic-hydrophilic balance of the carrier and/or substrate. However, relatively little has been studied about their effectiveness as carriers in membrane transport systems (Tondre and Derouiche 1990; Seno and Araki 1993). Since micelles are supramolecular aggregates, the properties of supramolecular carriers can be modified easily by incorporation of functional molecules without structural modification of the surfactant (scheme 2a). Use of a functional supramolecular carrier might be a convenient method for developing an artificial active transport system. 
For this purpose, we selected amphiphilic spiropyran derivatives, PC18, as a photochromic substrate (Ino et al 1994b). Interconversion between spiropyran (SP) and zwitterionic merocyanine (MC) can be controlled by photo-irradiation (scheme $2 b$ ).

In all solvents and reversed micellar solutions examined, PC18 showed normal photo-chromism, i.e., SP to MC by UV-light irradiation (100-W high-pressure mercury lamp, $300 \mathrm{~nm}<\lambda<400 \mathrm{~nm}$ ) and MC to SP by thermal process or Vis-light irradiation $(420 \mathrm{~nm}<\hat{\lambda})$. Increase of solvent polarity caused a blue shift of the absorption maximum $\left(\lambda_{\max }\right)$ of the photo-induced MC form of PC and concomitant increase of their half-lives $\left(t_{\frac{1}{3}}\right)$, which can be a good measure of the microenvironment around the $\mathrm{MC}$ unit in reversed micellar solutions. When the reversed micelles were saturated with water ( $p \mathrm{H} 6.0$ buffer solution), the $\lambda_{\max }$ of the $\mathrm{MC18}$ showed a blue shift and the $t_{\frac{1}{2}}$ increased (table 3 ). Therefore, the MC unit was solubilized near the water core of the reversed micelles, confirming that the $\mathrm{PC} 18$ was incorporated in the reversed micelles to form photoresponsive supramolecular carriers.

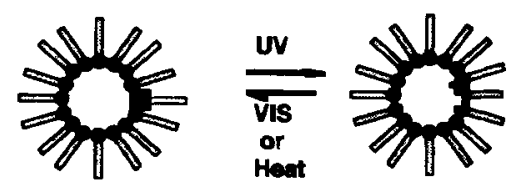

(a)

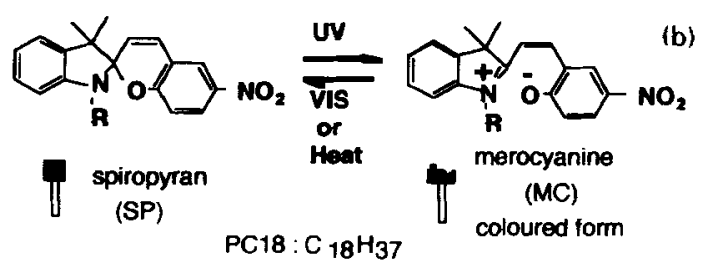

Scheme 2. SP-incorporated supramolecular carrier. (a) The supramolecular carrier; (b) photochromism of PC18.

Table 3. Absorption maxima $\left(\lambda_{\max }\right)$ and half-lives $\left(t_{t}\right)$ of MC form of PC18 in different reversed micellar systems at $25^{\circ} \mathrm{C}$

\begin{tabular}{lcr}
\hline & $\lambda_{\max }(\mathrm{nm})$ & $t_{\frac{1}{2}}(\mathrm{~s})$ \\
\hline Ethanol & 548 & 1100 \\
Acetone & 569 & 870 \\
Cyclohexane & 578 & 44 \\
$n$-Decane & 580 & 16 \\
AOT & 564 & 60 \\
AOT & 540 & 180 \\
TEGDE & 570 & 27 \\
TEGDE $^{\mathrm{a}}$ & 563 & 30 \\
\hline
\end{tabular}

$[\mathrm{PC} 18]=3 \times 10^{-5} \mathrm{M},[$ surfactant $]=100 \mathrm{mM}$;

${ }^{a}$ Reversed micellar solutions are saturated with $p \mathrm{H} 6.0$ buffer solutions 
Extraction of amino acids by the PC18-incorporated reversed micelles under UV-irradiation was studied at $p \mathrm{H} \mathrm{6.0} \mathrm{where} \mathrm{the} \mathrm{amino} \mathrm{acid} \mathrm{was} \mathrm{zwitterionic} \mathrm{(table} \mathrm{4).}$ Upon Vis-irradiation for $10 \mathrm{~min}$, the portion of the amino acids extracted presumably by the MC was efficiently released back to the aqueous phase. Contribution of the photochromic PC18 to the extraction of amino acid was much higher in the nonionic TEGDE (tetraethylene glycol dodecylether) reversed micellar systems and approximately twice the amount of amino acid was transferred into the organic phase under UV-irradiation compared with those under Vis-irradiation. Therefore, PC18-incorporated reversed micelles can serve as photo-responsive extraction systems for amino acids. Extraction by the reversed micellar system shows amino acid selectivity, which roughly coincides with the hydrophobicity of the side chain of the amino acid, thus indicating the importance of the side chain structure.

Photo-driven active transport of amino acid by PC18-incorporated reversed micelles through the $n$-decane liquid membrane was carried out in an $\mathrm{H}$-shaped tube $(\phi 10 \mathrm{~mm})$ at $20^{\circ} \mathrm{C}$. Two identical aqueous solutions containing $2.0 \mathrm{mM}$ of Trp and $2.0 \mathrm{mM}$ of Ala were separated by the PC18-incorporated TEGDE reversed micellar solution. Upon photo-irradiation, the Trp concentration on the Vis-irradiated side started increasing after some induction time period (figure 5). Mechanism of the photo-driven active transport of Trp by the functional reversed micelles is shown in scheme 3. On the other hand, the Ala concentration of both the sides remained unchanged during photo-irradiation, indicating that the functional TEGDE reversed micellar carrier has high amino acid selectivity. This selectivity in the transport system was essentially the same as that observed for amino acid extraction. The active transport of Trp by PC18 alone or the PC18-incorporated anionic AOT (bis(2ethylhexyl)sulfosuccinate) reversed micellar system was unsuccessful. As AOT reversed micelles alone have high ability to extract Trp into the organic phase, contribution of PC18 might be too small to induce active transport.

Table 4. Proportion of amino acids in the PC18-incorporated reversed micellar phase after equilibrium extraction from an aqueous buffer solution $\left(p \mathrm{H} \mathrm{6.0)}\right.$ at $20^{\circ} \mathrm{C}^{\mathrm{a}}$.

\begin{tabular}{|c|c|c|c|c|}
\hline \multirow[b]{2}{*}{ Surfactant } & \multirow[b]{2}{*}{ Amino acid } & \multicolumn{3}{|c|}{ Yield of transfer $(\%)$} \\
\hline & & $U^{b}$ & $\mathrm{Vis}^{\mathrm{b}}$ & Without $\mathrm{PC} 18^{\mathrm{c}}$ \\
\hline TEGDE & Trp & $16 \cdot 0$ & $8 \cdot 0$ & $6 \cdot 5$ \\
\hline TEGDE & Phe & $14 \cdot 3$ & $7 \cdot 6$ & $5 \cdot 9$ \\
\hline TEGDE & Tyr & $7 \cdot 5$ & 3.8 & $2 \cdot 0$ \\
\hline TEGDE & Ala & $2 \cdot 3$ & 1.4 & 0.5 \\
\hline AOT & $\operatorname{Trp}$ & $27 \cdot 0$ & $22 \cdot 5$ & $19 \cdot 3$ \\
\hline AOT & Phe & $24 \cdot 5$ & $20 \cdot 1$ & $16 \cdot 0$ \\
\hline None $^{d}$ & Trp & $7 \cdot 0$ & 0.0 & \\
\hline None $^{d}$ & Phe & 6.0 & 0.0 & \\
\hline
\end{tabular}

${ }^{\mathrm{a}}$ Conditions: organic layer: (100 mMAOT $+1.0 \mathrm{mM} \mathrm{PC18)}$ or (100 mM TEGDE $+100 \mathrm{mM}$ hexanol $+1.0 \mathrm{mM}$ PC18) $/ n$-decane; aqueous layer: $0.1 \mathrm{mM}$ amino acid/ $0.2 \mathrm{M} \mathrm{KH}_{2} \mathrm{PO}_{4}-\mathrm{NaOH}$ buffer. ${ }^{b}$ UV-light irradiation for $20 \mathrm{~min}$, and subsequently Vis-light irradiation for $10 \mathrm{~min} .{ }^{\mathrm{c}}$ Reversed micellar systems without PC18. ${ }^{\mathrm{d}} \mathrm{PC} 18$ alone. 


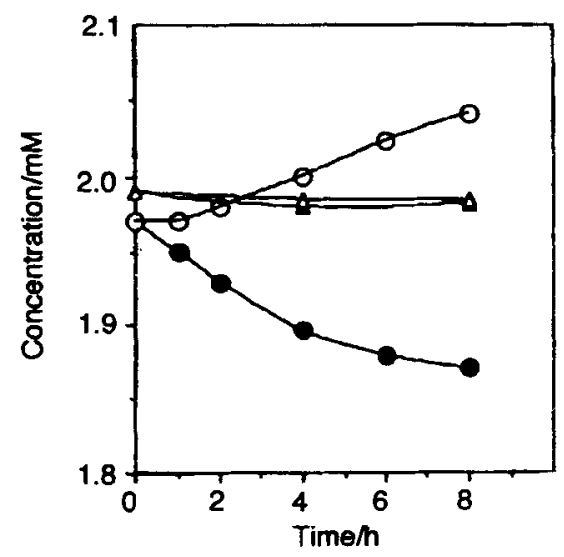

Figure 5. Time course of the change in $\operatorname{Trp}(\Theta)$ and Ala $(\boldsymbol{A})$ concentrations in the UV-irradiated and the $\operatorname{Trp}(O)$ and Ala $(\triangle)$ concentrations in the Vis-irradiated aqueous phases during the photo-driven transport by the PC18-incorporated TEGDE reversed micellar carrier at $20^{\circ} \mathrm{C}$. Initial amino acid concentrations in both aqueous solutions were $2 \mathrm{mM}$.

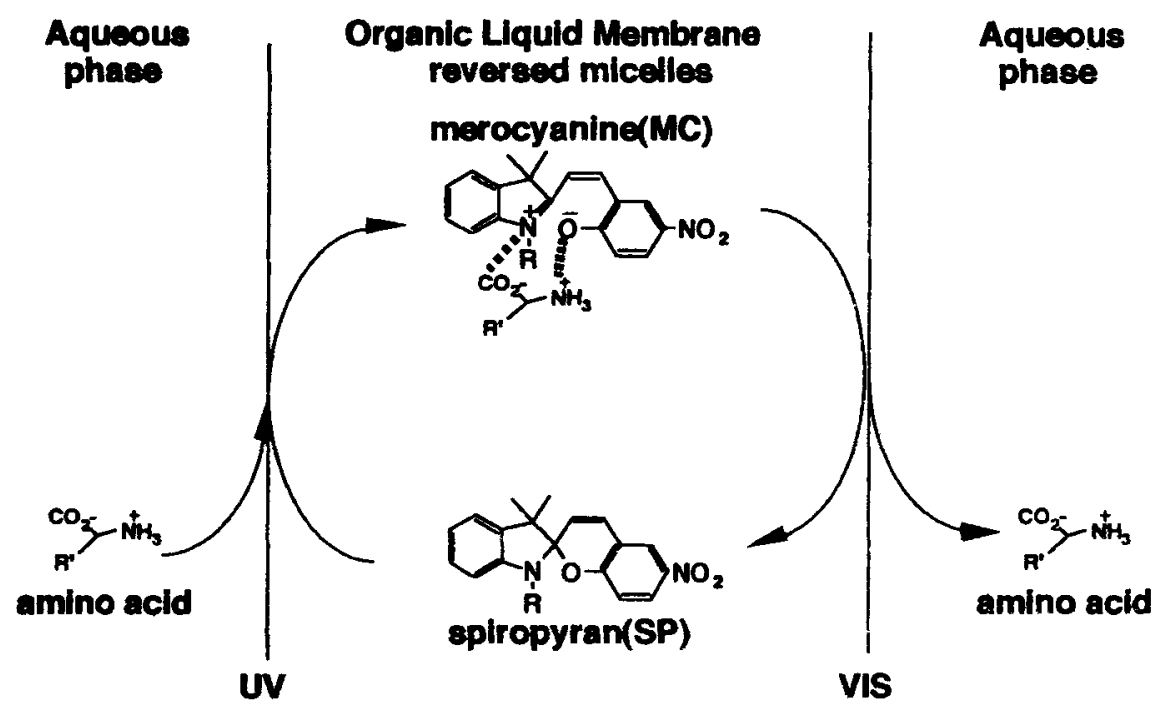

Scheme 3. Active transport of amino acid through a reversed micellar liquid membrane.

Thus, active and selective transport of Trp by PC18-incorporated TEGDE reversed micellar carrier was achieved. Photo-induced affinity switching of PC18 is the driving force of the active transport, while, the TEGDE reversed micelles provided a relatively polar environment in the $n$-decane phase in order to promote selective solubilization of the amino acids. A functional reversed micellar carrier can easily be prepared and tuned by incorporating functional molecules into micellar aggregates. Therefore, further investigation of reversed micelles as well as functional molecules may lead to the development of highly functional transport systems. 


\section{Metal complex-type carrier for $\mathrm{pH}$-induced active transport}

\subsection{Transport of anions by a novel complex-type carrier}

Affinity switching of the carrier in the membrane phase by the $p \mathrm{H}$ of external aqueous solutions can induce $p \mathrm{H}$-induced uphill transport by coupling with the $p \mathrm{H}$ difference. For example, naturally-occurring monensin is reported to induce uphill transport of metal ion by switching its affinity. In order to develop an efficient secondary active transport model, we designed a novel complex-type anion carrier that can switch its affinity by $\mathrm{pH}$ difference. To design the carrier, the following have to be taken into account;

- high substrate affinity at the uptake process but low affinity at the release process;

- appropriate mechanism to control the affinity-switching reversibly;

- suitable lipophilic-hydrophilic balance.

In addition, the carrier should have high thermal and chemical stability. A lipophilic transition metal complex is a suitable candidate for the functional anion carrier. Electrostatic and coordination interactions are expected to operate between cationic metal center and anions. These intermolecular interactions are relatively strong, and operate effectively not only in organic media but also in aqueous solutions. Therefore, high anion affinity can easily be attained by complex-type carriers. Electrostatic interaction with anions diminishes when the net charge of the complex becomes neutral. Total charge of the cationic complex can be reduced by introduction of a negative charge to the ligand moiety.

Divalent metal complexes of 6,6'-bis (benzoylamino)-2,2'-bipyridine $\left(\mathrm{babpH}_{2}\right)$ have the properties suitable for functional anion carriers (Yamada et al 1987, 1988; Araki et al 1993b). Reversible dissociation-association of the amide protons of the ligand takes place in weakly acidic to neutral $p \mathrm{H}$ range, providing an efficient tool to regulate the anion affinity (scheme 4). In order to tune the hydrophobic nature of the carrier, $\boldsymbol{n}$-hexyl groups are introduced to the parent complex. A novel complex-type carrier, $\mathrm{Cu}$ (II) complexes of 6,6'-bis (4-hexylbenzoylamino)-2, $2^{\prime}$-bipyridine $\left(\mathrm{LH}_{2}\right)$ undergoes reversible step-wise deprotonation of the amide moieties through a mono-deprotonated complex, $\mathrm{CuLH}^{+}$, into a fully-deprotonated complex, $\mathrm{CuL}$ (Araki et al 1993a, 1996).

Ligand-centered absorption at around $360 \mathrm{~nm}$ of the non-deprotonated complex in $\mathrm{CH}_{2} \mathrm{Cl}_{2}$ showed clear two-step change on addition of tetra- $n$-butylammonium (TBA) thiocyanate $\left(\mathrm{SCN}^{-}\right)$, but not on addition of TBA bromide or $p$-toluenesulfonate (tosylate). The spectral change is ascribed to the step-wise coordination of two $\mathrm{SCN}^{-}$to the cationic complex in square-planar symmetry from the axial position. Association constant for the first step $\left(K_{\mathrm{Cul}}\right)$ was too large to be determined from the spectral change, but that for the second step $\left(K_{\mathrm{Cu} 2}\right)$ was $\log K_{\mathrm{Cu} 2}=4.53\left(20^{\circ} \mathrm{C}\right)$. Axial coordination of $\mathrm{SCN}^{-}$was further supported by the red shift of the $d-d$ band of the $\mathrm{CuLH}_{2}^{2+}$ from $638 \mathrm{~nm}$ to $694 \mathrm{~nm}$ on addition of twice the molar amounts of TBASCN, since the weaker square-planar ligand field due to axial coordination decreases the $d$ - $d$ transition energy of the copper complex.

In the case of the deprotonated complex, no interaction of the complex with anions was observed by the electronic spectra. Since CuL has stronger square-planar ligand field evidenced from its blue-shifted $d-d$ absorption band at $554 \mathrm{~nm}$, not only electrostatic 


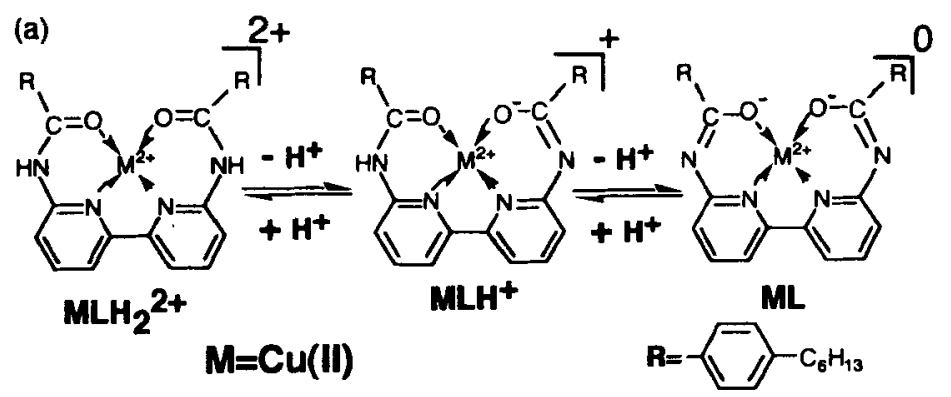

(b)

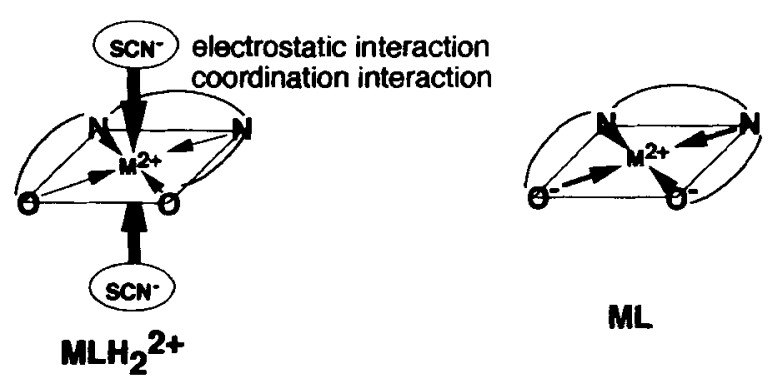

Scheme 4. (a) Dissociation of the amide units of the complex, and (b) their interaction with anions.

interaction but also coordination interaction from the axial position is much weaker in the neutral deprotonated complex. Thus, it is confirmed that the cationic complex in the non-deprotonated form has high $\mathrm{SCN}^{-}$affinity, while the fully-deprotonated complex shows poor anion affinity.

3.1a Uptake and release in two-phase and transport in three-phase systems: Reversible deprotonation of the complex in the organic layer is controlled by the $p \mathrm{H}$ of the aqueous solution. The complex $\left(2 \cdot 0 \times 10^{-3} \mathrm{M}\right)$, after contact with the same volume of

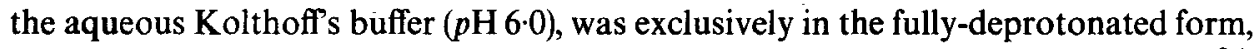
$\mathrm{CuL}$, but when the $\mathrm{pH}$ of the aqueous layer was 3.0 the major component was $\mathrm{CuLH}_{2}^{2+}$ (molar fraction $=0.84$ ). Table 5 shows the amount of the anion transferred to the organic layer after contact with the aqueous solution. Highly coordinating $\mathrm{SCN}^{-}$was efficiently extracted from the aqueous $p \mathrm{H} 3.0$ or 4.0 solution by the cationic $\mathrm{CuLH}_{2}^{2+}$ presumably due to the axial coordination of $\mathrm{SCN}^{-}$. Lipophilic tosylate was also transferred to the organic layer, but hydrophilic bromide was not extracted at all. Since nitrate is the counter anion of the non-deprotonated complex before contact with the buffer, extraction of tosylate is ascribed to its lipophilicity which favors ion-exchange with hydrophilic nitrate. The organic layer after extraction of anions from aqueous solutions was subjected to contact with fresh $p \mathrm{H} 6.0$ buffer solutions. Both $\mathrm{SCN}^{-}$and tosylate were released back to the aqueous $p \mathrm{H} \mathrm{6.0} \mathrm{solutions} \mathrm{(table} \mathrm{5).} \mathrm{The} \mathrm{complex} \mathrm{after}$ contact with the $p \mathrm{H} 6.0$ buffer was exclusively in the deprotonated form. Therefore, the 
Table 5. Uptake and release of the anions (percent, relative to the initial concentration of anion in the buffer solution) ${ }^{\mathrm{a}}$.

\begin{tabular}{|c|c|c|c|c|c|}
\hline \multirow[b]{3}{*}{$p \mathrm{H}$} & \multicolumn{5}{|c|}{ Anion $(\mathrm{NaX}) / \%$} \\
\hline & \multicolumn{2}{|c|}{ NaSCN } & \multicolumn{2}{|c|}{ Na Tosylate } & \multirow{2}{*}{$\frac{\mathrm{NaBr}}{\text { Uptake }}$} \\
\hline & Uptake & Release $^{\mathfrak{c}}$ & Uptake & Release $^{\mathfrak{c}}$ & \\
\hline$p \mathrm{H} 3.0$ & $54 \cdot 8$ & $48 \cdot 5$ & $-b)$ & & 0.0 \\
\hline$p \mathrm{H} 4 \cdot 0$ & $25 \cdot 8$ & $17 \cdot 3$ & $12 \cdot 3$ & $10 \cdot 8$ & 0.0 \\
\hline$p \mathrm{H} 6.0$ & $7 \cdot 2$ & 1.4 & 0.0 & 0.0 & 0.0 \\
\hline
\end{tabular}

[C]: $2.0 \times 10^{-3} \mathrm{~mol} \mathrm{dm}^{-3},[\mathrm{NaX}]: 4.0 \times 10^{-3} \mathrm{~mol} \mathrm{dm}^{-3}$; see $\S 3$ for details. 'Small amount of precipitate was observed at the interface after the aqueous and organic solutions were mixed. 'Organic layers after extraction were mixed with fresh $\mathrm{pH} 6.0$ buffer solutions; see $\S 3$ for derails.

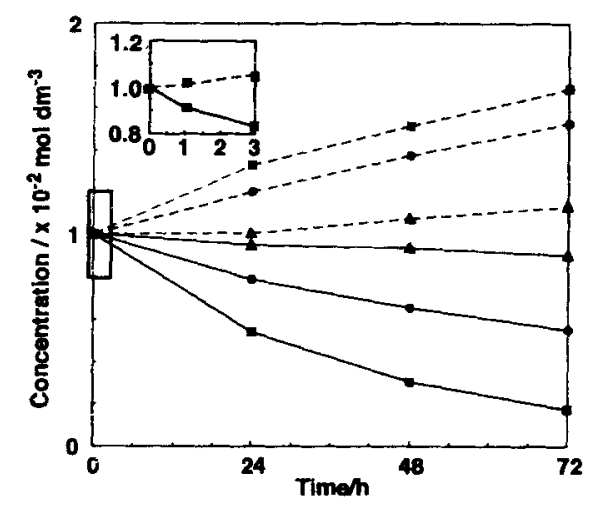

Figure 6. Time course of the change in $\mathrm{SCN}^{-}$concentration in the aqueous layer I (- $)$ and II (-- ) during uphill transport across $\mathrm{CH}_{2} \mathrm{Cl}_{2}$ layer mediated by $\mathrm{CuLH}_{2}^{2+}\left(1.11 \times 10^{-4} \mathrm{M}\right)$ at $20^{\circ} \mathrm{C}$. Initial concentrations of $\mathrm{SCN}^{-}$in both aqueous solutions were $1.0 \times 10^{-2} \mathrm{M}$. The layer II was set at $p \mathrm{H} 6.0$, while $p \mathrm{H}$ of the layer I was $3 \cdot 0(\square), 4 \cdot 0(0)$, and $5 \cdot 0(\Delta)$.

results confirmed that the affinity-switching of the carrier by $p \mathrm{H}$-induced amide deprotonation can control uptake and release of $\mathrm{SCN}^{-}$and tosylate.

Transport experiments were carried out at $20^{\circ} \mathrm{C}$ using a three-phase system, where two aqueous buffer solutions were separated by a $\mathrm{CuLH}_{2}^{2+} / \mathrm{CH}_{2} \mathrm{Cl}_{2}$ layer $\left(1 \cdot 11 \times 10^{-4} \mathrm{M}, 30 \mathrm{~cm}^{3}\right)$. The aqueous layers I (aq. I, $p \mathrm{H} \mathrm{3.0-5.0)} \mathrm{and} \mathrm{II} \mathrm{(aq.} \mathrm{II,} p \mathrm{H} \mathrm{6.0)}$ were identical in their volume $\left(10 \mathrm{~cm}^{3}\right)$ and $\mathrm{NaSCN}$ concentration $\left(1.00 \times 10^{-2} \mathrm{M}\right)$, though their $p \mathrm{H}$ values were different. When the $p \mathrm{H}$ of aq. I was 4.0 or 3.0 (figure 6). efficient uphill transport of $\mathrm{SCN}^{-}$took place from the aq. I to aq. II against concentration gradient. As the amounts of the $\mathrm{H}^{+}$and $\mathrm{SCN}^{-}$transported from aq. I after $72 \mathrm{~h}$ were almost the same, uphill transport of $\mathrm{SCN}^{-}$was quantitatively coupled with symport of $\mathrm{H}^{+}$. 
It is worth noting that only a small $\mathrm{pH}$ difference is required for efficient uphill transport of $\mathrm{SCN}^{-}$. To our knowledge, this is the first report of efficient uphill transport induced by such a small $p \mathrm{H}$ difference. Conventional carrier-mediated transport involves ion-exchange at both sides of the membrane. As is discussed in $\S 1$, higher substrate affinity of the carrier is favorable for the uptake process, but is unfavorable for the release process. Therefore, most of the $p \mathrm{H}$-driven uphill transport requires large $p \mathrm{H}$ difference across the membrane in order to establish efficient uptake and release simultaneously. In the case of the carrier reported here, protonation of the deprotonated complex is coupled quantitatively with uptake of counter anion(s), while deprotonation of the mono- or non-deprotonated complex induces concomitant release of the counter anion(s). As the anion-binding and affinity-switching sites are different within the carrier complex, strong anion-binding to the carrier does not interfere with the deprotonation of the amide groups to induce release of the bound anion(s) (scheme 4). Thus, affinity-switching of the carrier can easily by controlled by the $p \mathrm{H}$ of the aqueous layer, and $p \mathrm{H}$.difference sufficient to induce affinity-switching of the carrier can induce uphill transport.

Molar fractions of the complexes, $\mathrm{CuLH}_{2}^{2+}, \mathrm{CuLH}^{+}$and $\mathrm{CuL}$, after $3 \mathrm{~h}$ of the $\mathrm{SCN}^{-}$ transport were $0.41,0.19$ and 0.39 respectively. Therefore, the carrier in the system is either the non-deprotonated or the mono-deprotonated complex, and the contribution of $\mathrm{CuLH}_{2}^{2+}$ is higher in $\mathrm{SCN}^{-}$transport. On the basis of the assumption that twice the molar amounts of anion are transported by the carrier complex, turnover of the carrier is estimated and included in table 6. The transport mechanism of this system is illustrated in scheme 5 .

Lipophilic tosylate was also transported across the organic layer, but hydrophilic bromide was not transported at all (table 6). When tosylate and $\mathrm{SCN}^{-}$were present simultaneously in the aqueous layers, $\mathrm{SCN}^{-}$having higher coordination ability was selectively transported (table 6, no 6). The observed anion selectivity is explained by two factors, lipophilicity and coordination ability of the anions, at the uptake process. Anions having poor coordination ability are extracted in the organic layer as a counter anion of the carrier complex, where higher lipophilicity is favorable for extraction.

Table 6. Anion transport from the aqueous layers $\tilde{I}\left(10 \mathrm{~cm}^{3}\right)$ to II $\left(10 \mathrm{~cm}^{3}\right)$ across the $\mathrm{CH}_{2} \mathrm{Cl}_{2}$ layer containing $\mathrm{CuLH}_{2}^{2+}\left(1 \cdot 11 \times 10^{-4} \mathrm{M}\right.$ $30 \mathrm{~cm}^{3}$ ) at $20^{\circ} \mathrm{C}^{2}$

\begin{tabular}{llcccc}
\hline & & \multicolumn{4}{c}{ Concentration after $72 \mathrm{~h} / 10^{-2} \mathrm{M}$} \\
\cline { 3 - 6 } No. & Anion & $p \mathrm{H}$ & Layer I & Layer II $(p \mathrm{H} \mathrm{6.0)}$ & Turnover $^{\mathrm{c}}$ \\
\hline 1 & $\mathrm{SCN}^{-}$ & 3.0 & 0.17 & 1.69 & 10.0 \\
2 & $\mathrm{SCN}^{-}$ & 4.0 & 0.55 & 1.53 & 8.0 \\
3 & $\mathrm{SCN}^{-}$ & 5.0 & 0.90 & 1.13 & 2.0 \\
4 & Br $^{-}$ & 4.0 & 1.00 & 1.00 & 0.0 \\
5 & Tosylate & 4.0 & 0.77 & 1.21 & 3.0 \\
$6^{6}$ & Tosylate & 4.0 & 0.88 & 1.03 & 0.5 \\
& SCN & & 0.50 & 1.45 & 7.0 \\
\hline
\end{tabular}

${ }^{2}$ Initial anion concentrations in the aqueous layers I and II were $1.00 \times 10^{-2} \mathrm{M}$; ${ }^{b}$ the aqueous layers contained both tosylate and $\mathrm{SCN}^{-}$; ${ }^{c}$ turnover of the carrier after $72 \mathrm{~h}$ based on the assumption that twice molar amount of anion is transported by the carrier. 


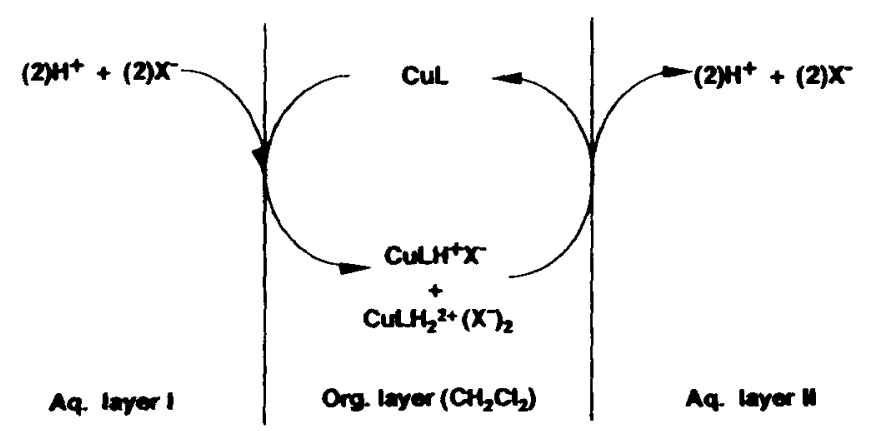

Scheme 5. Transport mechanism of anions $\left(\mathrm{X}^{-}\right)$.

However, direct coordination of $\mathrm{SCN}^{-}$to the metal center is much more advantageous in the extraction process, and $\mathrm{SCN}^{-}$is selectively transported even in the presence of tosylate.

Nickel (II) complex of $\mathrm{LH}_{2}$ also induced efficient uphill transport of $\mathrm{SCN}^{-}$by coupling with a $p \mathrm{H}$ difference as low as two (Lee et al 1996a). The simple one-step amide-deprotonation and $\mathrm{SCN}^{-}$coordination permitted quantitative analysis of the transport mechanism, though the details are not discussed here. Performance of the $\mathrm{Ni}(\mathrm{II})$ complex as the carrier is comparable to or slightly better than that of the $\mathrm{Cu}$ (II) complex.

3.2 Uphill transport of amino acids by complex-type carriers: The deprotonation of the amide groups of the complex alters not only the electrostatic interaction but also coordination interaction of the complex with substrates. Therefore, affinity-switching strategy is applicable to not only anions but also to substrates having metal coordination sites. Since many biologically important substrates have metal coordination sites in their structure, model secondary active transport systems for biomolecules can be developed by this complex-type carrier. Here, we tested the uphill transport of carbobenzoxy-histidine (Cbz-His) having imidazole as the metal-coordination site by the $\mathrm{Ni}(\mathrm{II})$ complex (Lee et al 1996b).

Axial coordination of the imidazole unit of $\mathrm{Cbz}$-His was confirmed from the spectral change of the non-deprotonated complex $\left(\mathrm{NiLH}_{2}^{2+}\right)$ in $\mathrm{CH}_{2} \mathrm{Cl}_{2}$ upon addition of $\mathrm{Cbz}-\mathrm{His}$ with a $1: 2$ association constant $\left(\log K_{\mathrm{Cbz}-\mathrm{His}}\right)$ of $8.30 \pm 0.03$. However, $\mathrm{Cbz}$-His did not cause any detectable spectral change of the deprotonated complex (NiL) at all.

In two-phase experiments, $10.8 \%$ of $\mathrm{Cbz}-\mathrm{His}$ in the aqueous $p \mathrm{H} 3.0$ solution was transferred to the organic layer by $\mathrm{NiLH}_{2}^{2+}$ (table 7). Since no transfer of Cbz-His was observed without the complex, hydrophilic Cbz-His was extracted into the organic phase by $\mathrm{NiLH}_{2}^{2+}$. Presence of lipophilic but weak coordinating $\mathrm{ClO}_{4}^{-}$ increased the molar fraction of the $\mathrm{NiLH}_{2}^{2+}(100 \%)$, since lipophilic counter anion increases the stability of the non-deprotonated complex in the organic layer. Amounts of the extracted $\mathrm{Cbz}$-His were also increased by $\mathrm{NaClO}_{4}$, and this synergistic effect might be ascribed to the co-extraction of $\mathrm{Cbz}-\mathrm{His}$ and $\mathrm{ClO}_{4}^{-}$into the organic layer. Extraction of Cbz-His was primarily due to the coordination interaction between the imidazole and the metal center. The complex in the organic layer was exclusively in the fully-deprotonated form after contact with the aqueous $p \mathrm{H} 10.0$ solutions, and no 
Table 7. Uptake of the Cbz-His (percent) relative to the initial concentration of anion in the buffer solution ${ }^{\text {a }}$.

\begin{tabular}{|c|c|c|c|}
\hline \multirow{2}{*}{$\frac{\text { Complex }}{\text { Counter anion }}$} & \multirow{2}{*}{$\frac{\text { None }}{\mathrm{NaClO}_{4}}$} & \multicolumn{2}{|c|}{$\mathrm{NiLH}_{2}^{2+}$} \\
\hline & & None & $\mathrm{NaClO}_{4}$ \\
\hline $\mathrm{pH} 3.0$ & 0.0 & $30 \cdot 0$ & $46 \cdot 0$ \\
\hline $\mathrm{pH} 6.0$ & 0.0 & $12 \cdot 0$ & $21 \cdot 0$ \\
\hline $\mathrm{pH} 10.0$. & 0.0 & 0.0 & 1.0 \\
\hline
\end{tabular}

aOrganic phase, $\mathrm{CH}_{2} \mathrm{Cl}_{2}\left(2 \mathrm{~cm}^{3}\right)$ containing $2 \times 10^{-3}$ moldm ${ }^{-3}$ of $\mathrm{NiLH}_{2}^{2+}$; aqueous phase, buffer solution $\left(2 \mathrm{~cm}^{3}\right)$ containing $2 \times 10^{-3} \mathrm{~mol} \mathrm{dm}^{-3}$ of $\mathrm{Cbz}$-His and $2 \times 10^{-2} \mathrm{~mol} \mathrm{dm}^{-3}$ of $\mathrm{NaClO}_{4}$.

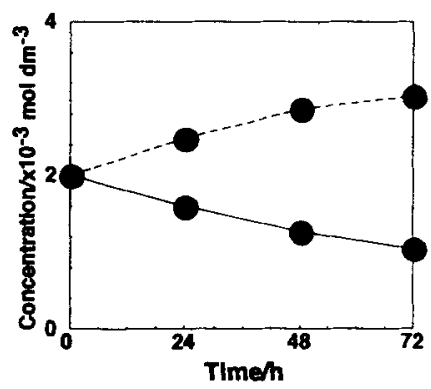

Figure 7. Time course of the change in $\mathrm{Cbz}$-His concentration in the aqueous layer I $\left(p \mathrm{H} 3 \cdot 0,-\frac{1}{)}\right.$ and II $(p \mathrm{H} \mathrm{10} \cdot 0,---)$ during uphill transport across the $\mathrm{CH}_{2} \mathrm{Cl}_{2}$ layer mediated by $\mathrm{NiLH}_{2}^{2+}\left(2.0 \times 10^{-4} \mathrm{M}\right)$ at $20^{\circ} \mathrm{C}$. Initial concentrations of $\mathrm{Cbz}$-His in both aqueous layers were $2 \times 10^{-3} \mathrm{M}$.

extraction of $\mathrm{Cbz}$-His was observed at all. Therefore, the non-deprotonated complex has high extraction ability toward $\mathrm{Cbz}$-His while the deprotonated complex has poor extraction ability.

In the three-phase systems, the carrier complex induced uphill transport of $\mathrm{Cbz}-\mathrm{His}$ across the organic membrane from the $p \mathrm{H} 3.0$ aqueous layer to the $p \mathrm{H} 6.0$ or 10.0 aqueous layer (figure 7). Uphill transport requires the presence of $\mathrm{NaClO}_{4}$ in the aqueous phase. No transport of $\mathrm{Cbz}-\mathrm{His}$ was observed without $\mathrm{NiLH}_{2}^{2+}$ in the organic layer or a $p \mathrm{H}$ difference between two aqueous layers. Therefore, it is clear that $\mathrm{NiLH}_{2}^{2+}$ is the carrier that induces uphill transport of $\mathrm{Cbz}$-His by coupling with the $\mathrm{pH}$ difference across the membrane. Without $\mathrm{NaClO}_{4}$, no practical uphill transport was observed at all. From the synergistic effect of $\mathrm{NaClO}_{4}$ observed for uptake of $\mathrm{Cbz}$-His, the role of $\mathrm{NaClO}_{4}$ can best be interpreted as a lipophilic but weak coordinating counter anion that helps extraction of hydrophilic $\mathrm{Cbz}$-His into the organic layer.

Thus, the affinity-switching strategy by using the functional $\mathrm{Ni}$ (II) complex-type carrier is effective for the uphill transport of $\mathrm{Cbz}-\mathrm{His}$ that has imidazole as the metal coordination site. Since many biomolecules have metal-coordination sites in their structure, the authors believe that the result presented here may open wide applicability of the affinity-switching strategy for the uphill transport of biologically important molecules. 


\section{Conclusion}

Information processing and intercellular communication in multicellular living systems are mediated not by electrons but by chemical substances, and information is stored, transmitted, and processed in a form of molecular structure of the substrate. Active transport plays an indispensable role in these processes. Studies on artificial active transport systems might provide the way to develop artificial molecular-based information processing and transmission systems.

In this article, we demonstrated that the affinity-switching concept is effective for designing an artificial active transport model. Properly tuned transport systems and well-designed carriers are essential for efficient active transport.

\section{References}

Araki K, Lee S-K, Otsuki J and Seno M 1993a Chem. Lett. 493

Araki K, Kuboki T, Otohata M, Kishimoto N, Yamada M and Shiraishi S 1993b J. Chem. Soc., Dalton Trans. 3647

Araki K, Lee S-K and Otsuki J 1996 J. Chem. Soc., Dalton Trans. 1367

Bogdanov M and Dowhan W 1995 J. Bio. Chem. 270732

Cross R L 1994 Nature (London) 370594

Hiratani K, Hirose T, Kasuga K and Saito K 1992 J. Org. Chem. 577083

Ino M, Otsuki J, Araki K and Seno M 1994a J. Membrane Sci. 89101

Ino M, Tanaka H, Otsuki J, Araki K and Seno M 1994b Colloid Polym. Sci. 272151

Irie $M$ and Kato M $1985 \mathrm{~J}$. Am. Chem. Soc. 1071024

Jessenmarshall A E, Paul N J and Brooker R J 1995 J. Bio. Chem. 27016251

Kishii N, Araki K and Shiraishi S 1985 J. Chem. Soc., Dalton Trans. 373

Lanyl J K 1995 Nature (London) 375461

Lee S-K, Kumasaka Y, Otsuki J and Araki K 1996a Bull. Chem. Soc. Jpn. 691213

Lee S-K, Yamada H, Mishina S and Araki K 1996b J. Chem. Soc., Chem. Commun. 1179

Lehn J-M 1988 Angew. Chem., Int. Ed. Engl. 2790

Lucia M, Valeria P I and Radu M 1992 Rev. Roum. Chim. 371175

MaClelland R A, Banait N and Steenken S 1989 J. Am. Chem. Soc. 1112929

Seno M and Araki K 1993 New functionality materials (eds) T Tsuruta, M Seno and M Doyama (Amsterdam: Elsevier Science) vol. C, pp. 465-472

Shimizu T and Yoshizawa M 1983 J. Membrane Sci. 131

Shinkai S, Shigematsu K, Kusano Y and Manabe O 1982 J. Chem. Soc., Perkin. Trans. I 2735

Tondre C and Derouiche A 1990 J. Phys. Chem. 941624

Winkler J D, Deshayes K and Shao B 1989 J. Am. Chem. Soc. 111769

Yamada M, Araki K and Shiraish S 1987 Bull. Chem. Soc. Jpn. 603149

Yamada M, Araki K and Shiraish S 1988 Bull. Chem. Soc. Jpn. 612767 